\title{
Junção e(m) aquisição: aspectos morfossintáticos e cognitivos
}

Sanderléia Roberta Longhin-Thomazi (UNESP1)

Recebido 16, jan. 2011 / Aprovado 7, mar. 2011

\section{Resumo}

Neste trabalho, investigo possíveis correlações entre tendências subjacentes aos usos dos mecanismos de junção em textos de sujeitos em fase de aquisição de escrita e tendências sobre desenvolvimento de juntores na história da língua. Trata-se, de certa maneira, de trazer novas luzes acerca do paralelo entre ontogenia e filogenia, nos moldes de Kortmann (1997), que sustenta, para a aquisição de esquemas de junção e para a mudança dos juntores ao longo do tempo, direções que sinalizam uma complexidade crescente, verificável tanto de um ponto de vista morfossintático, como de um ponto de vista semântico-cognitivo.

Palavras-chave: aquisição; junção; cognição; história 


\section{Introdução}

Neste trabalho, investigo aspectos morfossintáticos e cognitivos da junção em uma amostra longitudinal de textos produzidos por duas crianças, nos primeiros anos de aquisição de escrita institucionalizada. Para isso, lanço mão de um modelo de junção de orientação funcionalista (HALLIDAY, 1985), que contempla as opções de arquitetura sintática pareadas com as relações semânticas, aliado a pressupostos da mudança linguística por gramaticalização. A questão central é verificar em que medida tendências filogenéticas, que apontam para o aumento de informação gramatical e de complexidade cognitiva, ajudam a explicar os fatos de aquisição (KORTMANN, 1997).

Não se trata de insistir nas teses já tão debatidas que consistem em atribuir simplicidade à parataxe e complexidade à hipotaxe, e em sustentar que entre elas haveria uma passagem progressiva, da composição menos para a mais complexa, recuperável na filogênese e na ontogênese. Dessas teses derivam generalizações de que a parataxe é a sintaxe da língua falada, da língua das crianças e dos aprendizes, e também das línguas históricas em suas fases pretéritas. À maneira de La Fauci (2007), entendo que a fragilidade dessas afirmações e que o contraste que elas alimentam entre parataxe e hipotaxe se devem, em grande parte, à desconsideração das tradições discursivas (KABATEK, 2006) e à correlação equivocada que se estabelece entre simplicidade e oralidade.

O que proponho é verificar por quais mecanismos de junção os sentidos são codificados nos textos infantis ao longo do período inicial de alfabetização e investigar um possível paralelo entre ontogenia e filogenia, sem perder de vista o contínuo processo de aquisição de novas tradições discursivas ${ }^{2}$ (TDs, daqui em diante), já que tudo o que se enuncia, seja na modalidade falada ou escrita, se enuncia dentro de uma TD, de um gênero ou de um modo de dizer sócio-historicamente convencionalizado (KABATEK,

${ }^{2}$ Este trabalho é parte do resultado da pesquisa de pós-doutoramento que realizei na Universidade de Tübingen, sob orientação do Prof. Dr. Johannes Kabatek (CNPq: 302670/2008-4/ Fapesp: 09/53614-0).

${ }^{3}$ Nos moldes de Coseriu, o sistema compreende um conjunto de possibilidades técnicas do falar, em que somente parte é realizada. A norma, por sua vez, restringe as possibilidades do sistema. Compreende a escolha usual entre as opções oferecidas pelo sistema. 2006). Desse ponto de vista, as afirmações sobre os esquemas de junção empregados pelas crianças só podem ser legitimadas com a consideração das TDs.

Aproximando-me da concepção de linguagem e do modelo de produção verbal proposto na obra de Coseriu, e refinado nos trabalhos de Koch (1997) e de Oesterreicher (1997), assumo que, para a produção de enunciados escritos, a criança lida simultaneamente com dois conjuntos de regras, as regras idiomáticas, que estão no domínio da língua histórica particular (sistema e norma $\left.{ }^{3}\right)$, e as regras discursivas, que estão no domínio das TDs (que englobam atos de fala, gêneros, tipos textuais, estilos, formas literárias), que se referem mais propriamente aos modos de dizer tradicionais que regulam a produção e a recepção dos discursos. Dessa perspectiva, os enunciados dos textos infantis podem ser 
tomados como registro do grau de envolvimento da criança tanto com as regras do sistema como com as da tradição.

\section{Pressupostos e expectativas}

Com base em Kabatek (2006), parto do pressuposto de que as TDs condicionam o uso de determinadas construções linguísticas e também, na direção inversa, que a combinação de certas construções constitui traço caracterizador de TDs. Kabatek lança mão de uma metodologia estatística para identificação de diferentes tradições e, inspirado na proposta multidimensional de Biber (1988), que analisa traços linguísticos e situacionais para disposição dos gêneros em um contínuo, sugere uma redução dos parâmetros de análise e elege a junção para a distinção entre TDs, numa abordagem que conjuga tipos de juntores, frequência relativa e grau de complexidade. Para Kabatek, a junção é, por excelência, o fenômeno que permite a apreensão da(s) TD(s) em que um texto se insere.

Pressuponho também que a aquisição de TDs seja processual, como argumenta Oesterreicher (1997), que prevê para a aquisição etapas de identificação, habituação e legitimação. Segundo ele, a conformação às regras nunca se dá de modo mecânico, mas há sempre uma inserção gradual que passa por um 'núcleo duro', que tem propriedades bastante fixadas, e por núcleos variáveis, que se referem à face composicional das tradições. Como fiz em trabalhos anteriores, proponho abordar o princípio da composicionalidade das TDs no âmbito específico da junção, quando entram em jogo as escolhas que a criança faz sobre como juntar. Essas escolhas são sempre perpassadas por alguma percepção da criança acerca do que é fixo e do que é lacunar na tradição, e refletem um pouco do modo cambiante como a criança se insere nas regras idiomáticas e discursivas, para a construção de uma escrita.

Pressuponho ainda que antes da inserção nas práticas formais de letramento a criança já circula por TDs típicas da oralidade, e essa oralidade é sempre atravessada, em maior ou menor grau, por letramentos, a depender de sua vivência. Assim, quando chega à escola, a criança tem um grau de letramento. A concepção de letramento que sustento excede o contexto educacional e equivale a um processo mais amplo de natureza sócio-histórica relacionado às práticas de leitura e de escrita. A alfabetização é, portanto, apenas um tipo de letramento. Essa visão se compatibiliza com aquela de Street (2006), no âmbito da antropologia, em que as práticas de letramento são modos variados e complexos de representar os significados de ler e escrever, em diferentes contextos sociais, em meio a relações de poder e ideologia. São, para o autor, práticas constitutivas da identidade dos indivíduos, associadas a papeis sociais assumidos ou recusados. 
No contexto desses pressupostos, defendo que o estudo de fenômenos de aquisição deve necessariamente contemplar a inserção dos enunciados em TDs, e buscar um entendimento de que são indissociáveis as relações entre oral/letrado, enquanto práticas sociais, e entre falado/escrito, enquanto práticas linguísticas e sociais. Portanto, neste trabalho, minhas expectativas são as de: (i) que a escolha da forma de junção nos textos infantis é, pelo menos em parte, regida pela TD; (ii) que na escrita inicial infantil tradição letrada e tradição oral apareçam mescladas, constituindo-se mutuamente; e, (iii) que evidências dessa constituição heterogênea possam ser recuperadas na morfossintaxe do material escrito, especificamente quando se observa os esquemas de junção.

2. Junção: aspectos morfossintáticos e cognitivos

Para análise da junção, adoto um modelo funcionalista de "modificação" de orações (HALLIDAY, 1985; MARTIN et. al., 1997), que pressupõe a não-discretude dos processos de junção e o cruzamento entre informações sintáticas e semânticas. Nessa proposta, os juntores são analisados a partir do encontro entre duas dimensões: (i) o sistema de taxe, que diz respeito às relações de interdependência entre as orações; e, (ii) o sistema semântico, que diz respeito às relações de sentido. As opções do sistema de taxe são parataxe e hipotaxe, cuja distinção repousa, em princípio, no estatuto gramatical das orações envolvidas: se as orações são de mesmo estatuto, a construção é paratática; mas se os estatutos são desiguais, uma oração é modificadora e a outra nuclear, a construção é hipotática. Esse modelo tem a vantagem de dar conta do fato de que qualquer relação semântica pode se resolver em diferentes ambientes sintáticos, com arranjos que são tipicamente paratáticos, hipotáticos ou que estão na fronteira indecisa entre parataxe e hipotaxe, o que coloca em questão aspectos da abordagem tradicional em termos de coordenação e subordinação.

As relações semânticas são diversas e, em razão da predisposição derivacional existente entre elas, é possível ordená-las em função de maior ou menor complexidade, conforme proposto por Kortmann (1997), em estudo tipológico sobre gramaticalização de juntores adverbiais em línguas européias. Kortmann (1997) estabelece quatro macro-sistemas semântico-cognitivos, dentro dos quais se desdobram conjuntos de relações com elos de parentesco, que ajudam a explicar padrões de polissemia. São elas: tempo, modo, lugar e CCCC (causa, condição, concessão, contraste). Segundo ele, do ponto de vista histórico, a mudança semântica é fortemente direcional, pois os caminhos são condicionados pelas relações polissêmicas entre os sistemas semânticos, com vistas ao aumento de complexidade, capturado pelo Esquema 1, que mostra afinidades maiores e menores entre as relações semânticas: todas as relações podem dar lugar a CCCC, mas não vice-versa; lugar e modo não têm afinidades semânticas e alimentam os demais 
sistemas; tempo é o canal de derivação mais importante para as relações CCCC.

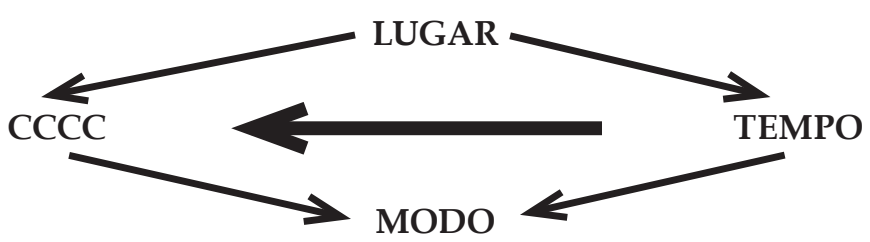

Esquema 1: Macroestrutura do universo semântico das relações racionais (Kortmann, 1997)

Nessa perspectiva, Kortmann (1997) propõe estender da filogênese para a ontogênese a investigação das tendências em mudança semântica envolvendo juntores, particularmente o desenvolvimento das relações de CCCC na linguagem infantil. Com base nos resultados de Reilly (1986), Bloom et al. (1980) e Bowerman (1986), Kortmann sustenta que, assim como na filogênese as direções na mudança semântica sinalizam uma complexidade cognitiva crescente, na ontogênese a ordem preferencial de aquisição dos esquemas de junção também segue um gradiente cognitivo similar, com relações de derivação em que os sentidos mais básicos alimentam os sentidos mais complexos: "os significados aprendidos posteriormente (CCCC) incorporam todos os significados antes aprendidos" (BOWERMAN, 1986, apud KORTMANN, 1997).

Ainda quanto à cognição, a complexidade pode ser avaliada à luz de uma ambiguidade que decorre da inserção dos juntores em domínios de interpretação. Sweetser (1991) reúne evidências de que um mesmo juntor pode estabelecer valores diversos, entre fatos do mundo sociofísico, entre etapas de um raciocínio lógico e entre momentos de uma argumentação. A autora defende que há um trânsito unidirecional entre esses domínios e que esse trânsito dá sustentação a uma importante tendência filogenética, segundo a qual os significados abstratos derivam dos concretos e, portanto, são historicamente mais tardios.

\section{O estatuto dos dados de escrita}

Vários trabalhos já destacaram a relevância de dados procedentes do processo de aquisição de escrita, argumentando em favor do potencial desses dados para o fornecimento de pistas:

para a formulação de hipóteses explicativas sobre características da linguagem oral, na medida em que a criança, ao elaborar hipóteses sobre a escrita, estará procurando representar uma linguagem que até então vinha utilizando exclusivamente de forma oral, em contextos que favorecem a manifestação de estruturas típicas da oralidade (ABAURRE, 1990). 
Nesta pesquisa, a decisão pelo corpus de enunciação escrita para explicação de fatos ontogenéticos encontra respaldo também no estatuto teórico que atribuo à relação fala/escrita. Minha perspectiva descarta a separação discreta entre fala e escrita e se aproxima, em parte, das propostas que abordam as diferenças entre essas modalidades em termos de contínuo tipológico, tal como defendido por Marcuschi (2001) e por Koch e Oesterreicher (1994, 2007). Segundo Marcuschi, os fenômenos de fala e escrita devem ser examinados enquanto fatos linguísticos vinculados a saberes sociais, o que permite pensar em um contínuo de gêneros discursivos com mais características de fala ou de escrita. Koch e Oesterreicher também recusam postulações dicotômicas e sustentam uma distinção escalar, de fronteiras pouco claras, entre o falado e o escrito. Para eles, essas noções são solidárias e devem ser avaliadas a partir de dois parâmetros: o canal de realização (fônico e gráfico) e a cognição, que torna mais claro o entrelaçamento entre o falado e o escrito. As atividades sociais pela linguagem, afirmam Koch e Oesterreicher, circulam por diferentes tipos de texto, numa escala cognitiva fundada na fala e na escrita ou, mais propriamente, numa oralidade e numa escrita concepcionais.

Rejeito explicações fundadas em possíveis relações de interferência da fala na escrita e assumo que, no processo inicial de inserção na escrita convencional, a criança já traz na "memória comunicativa" (OESTERREICHER, 1997) esquemas textuais, adquiridos em práticas sociais orais e letradas até então experimentadas. Por isso, a expectativa é a de que os textos das crianças registrem a convivência entre diferentes fontes de saber, provenientes de práticas sociais orais e letradas. É essa convivência que está subjacente à concepção de escrita heterogênea, desenvolvida em Corrêa (2004), em que fala e escrita são modalidades de enunciação relacionadas à circulação dos sujeitos pelas práticas sociais, havendo entre elas uma indissociabilidade que licencia a apreensão de características de enunciados falados no produto escrito.

\section{As questões}

(i) Se os esquemas de junção de um texto, com suas possibilidades de realização quanto à arquitetura sintática e relações semânticas, em termos quantitativos e qualitativos, constituem um fenômeno privilegiado para a apreensão da TD na qual o texto se insere, em que medida as formas de junção, nos textos infantis, são reveladoras do processo gradual de aquisição de regras idiomáticas e discursivas?

(ii) Se diacronicamente nas línguas as relações em nível epistêmico, próximas à experiência mental, derivam das relações objetivas entre fatos do mundo, próximos à experiência sociofísica, e se as construções que refletem representações de experiências do mundo são mais facilmente assimiladas do 
que construções que refletem etapas do raciocínio, até que ponto os dados de aquisição de escrita são reveladores de tendências que direcionam a uma complexidade crescente na morfossintaxe e na cognição?

\section{Material e Métodos}

Utilizo parte de um banco de dados ${ }^{4}$ que reúne produções textuais de alunos de duas escolas públicas de São José do Rio Preto/SP, localizadas em bairros de periferia. As coletas foram feitas quase que quinzenalmente, nas aulas de língua portuguesa, ao longo dos anos de 2001 a 2004, a partir da aplicação de propostas que visavam obter textos de tradições discursivas diversas. Assim, os mesmos alunos foram acompanhados durante as quatro primeiras séries do Ensino Fundamental. Para a pesquisa, selecionei as produções textuais de dois sujeitos, denominados E1 e E2, com base nos critérios: (i) maior frequência na realização das propostas; e, (ii) condições iniciais de escrita próximas às convenções. Portanto, o corpus é constituído de 102 textos:

\begin{tabular}{lccccc}
\hline Sujeitos & $\mathbf{2 0 0 1}$ & $\mathbf{2 0 0 2}$ & $\mathbf{2 0 0 3}$ & $\mathbf{2 0 0 4}$ & TOTAL \\
\hline $\begin{array}{l}\text { E1: } \\
\text { PHP }\end{array}$ & 14 & 15 & 11 & 13 & 53 \\
\hline $\begin{array}{l}\text { E2: } \\
\text { AGS }\end{array}$ & 11 & 14 & 11 & 13 & 49 \\
\hline
\end{tabular}

Quadro 1: Número de textos produzidos pelos sujeitos nos 4 anos do Ensino Fundamental

Quanto ao método, conjugo as abordagens quantitativa e qualitativa e percorro duas etapas principais: (i) mapeamento dos esquemas de junção dos textos, com a caracterização qualitativa dos juntores baseada no cruzamento entre os parâmetros sintático e semântico já esboçados; e, (ii) submissão dos dados ao programa estatístico TraDisc, para obtenção das frequências e dos juntogramas que subsidiam as análises. O TraDisc é um programa computacional para anotação de corpora em formato XML, de-

${ }^{4} \mathrm{O}$ banco de dados sobre aquisição de escrita infantil foi constituído para subsidiar as pesquisas do Grupo de Pesquisa Estudos sobre a linguagem (GPEL/CNPq processo 400183/20099), coordenado pelo Prof. Dr. Lourenço Chacon. As propostas de produção textual foram elaboradoras e aplicadas pela pesquisadora Cristiane C. Capristano, enquanto pós-graduanda do IBILCE/UNESP. senvolvido inicialmente para identificar e anotar juntores em um corpus, contudo sua utilização pode ser estendida para qualquer outro traço linguístico que tenha uma ou duas dimensões.

\section{Os esquemas de junção nos textos infantis}

O mapeamento dos esquemas de junção no corpus, sistematizado no Quadro 2, mostra que os sujeitos optam preferencialmente por determinados esquemas de junção, revelando tendências: o juntor e tem frequência elevada, atua na codificação de quase todas as relações de sentido, combinado ou não com advérbios juntivos; a justaposição (representada por $\varnothing$ ) é um recurso também utiliza- 
do com frequência, sobretudo para a relação de tempo e adição $0^{5}$; juntores morfologicamente complexos como perífrases conjuncionais quase não aparecem ${ }^{6}$; e, todas as relações de sentido, exceto concessão, são mostradas nos textos, em frequência variável.

\begin{tabular}{|c|c|c|c|c|c|c|c|}
\hline & Adição & Alter. & Modo & Tempo & Contraste & Causa & Condiç. \\
\hline Parataxe & $\begin{array}{c}\varnothing(12,3) \\
\text { e } \mathbf{( 5 4 , 0 )} \\
\text { e também } \\
(0,9) \\
\text { e ainda }(0,2) \\
\text { e aí }(0,2)\end{array}$ & Ou $(4,1)$ & e $\operatorname{assim}(0,5)$ & $\begin{array}{c}\varnothing(4,8) \\
\text { e }(\mathbf{5 4 , 1 )} \\
(\mathrm{e}) \text { aí }(4,1) \\
(\mathrm{e}) \text { depois } \\
(5,1) \\
(\mathrm{e}) \text { então } \\
(0,2) \\
\text { e enfim }(0,2) \\
\text { antes }(0,1) \\
\text { primeiro } \\
(1,2)\end{array}$ & $\begin{array}{c}\varnothing(0,4) \\
\text { e }(1,2) \\
\text { mas }(5,6) \\
\text { só que } \\
(1,2) \\
\text { já }(0,5) \\
\text { e já }(0,5)\end{array}$ & $\begin{array}{c}\varnothing(0,8) \\
\text { e }(6,0) \\
\text { porque }(7,4) \\
\text { então }(0,9) \\
\text { aí }(0,5) \\
\text { e por isso } \\
(0,2) \\
\text { e agora } \\
(0,26)\end{array}$ & $\begin{array}{l}\varnothing(0,1) \\
\text { e }(0,2)\end{array}$ \\
\hline Hipotaxe & & & $\begin{array}{l}\text { para }(16,9) \\
\text { como }(0,7) \\
\text { mais/menos } \\
\text { do que }(1,0)\end{array}$ & $\begin{array}{c}\text { quando }(5,0) \\
\text { gerúndio } \\
(5,3) \text { hora } \\
\text { que }(0,5) \\
\text { antes/depois } \\
\text { de }(0,7)\end{array}$ & & $\begin{array}{c}\text { porque }(3,2) \\
\text { por causa } \\
\text { que }(0,2) \\
\text { por }(0,9)\end{array}$ & se $(3,9)$ \\
\hline
\end{tabular}

Quadro 2: frequência (em 1000 palavras) dos juntores nos textos de aquisição de escrita infantil

No Quadro 2, a comparação entre os horizontes da parataxe e da hipotaxe faz sobressair a preponderância da parataxe, em termos quantitativos e qualitativos. Esses dados, cruzados com as informações do Gráfico 1, que mostra em números absolutos os resultados para o eixo tático, em perspectiva longitudinal, permitem uma generalização: a produção de sentido nos textos infantis, durante todo o percurso de quatro anos, se faz por meio de uma considerável complexidade de relações semânticas que se resolve quase que invariavelmente por meio da parataxe.

\footnotetext{
${ }^{5} \mathrm{Na}$ adição neutra, assim em certos usos de "aí" e "então", $e$ atua na progressão discursiva, num contínuo movimento de avanço pelo acréscimo constante de informação nova.

${ }^{6}$ As poucas perífrases encontradas no corpus "só que, por causa que, hora que" - resultam de processos mais recentes de gramaticalização na língua.
}

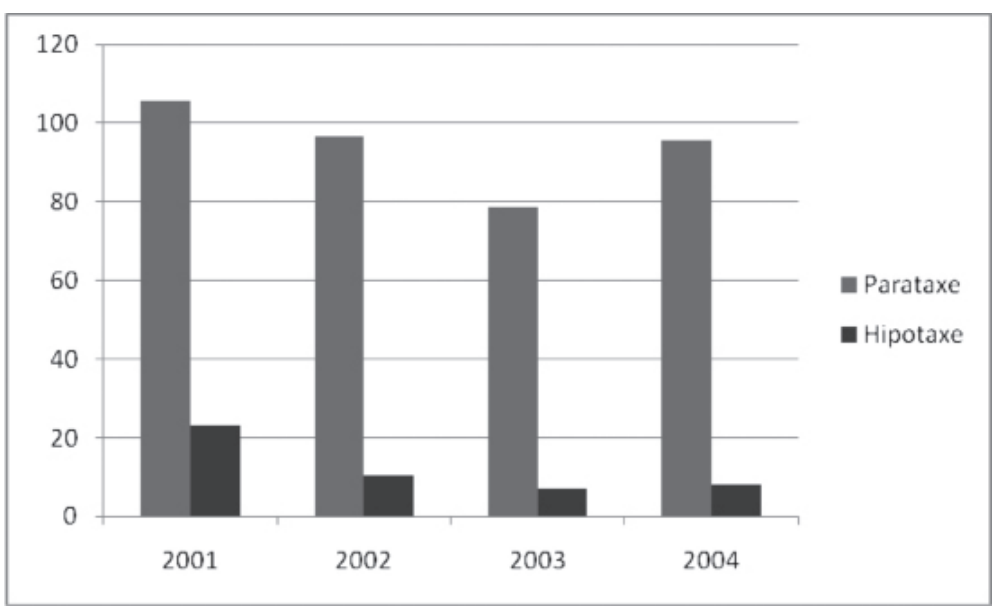

Gráfico 1: Eixo tático em perspectiva longitudinal 
Diante desses resultados e, tendo em vista as expectativas e questões levantadas anteriormente, a partir daqui, a análise segue duas vias. Em uma delas, nas seções 7.1 e 7.2, busco justificar a prevalência da parataxe nos quatro anos. Como recuso associar parataxe à simplicidade sintática, os argumentos são buscados na noção de TD e nas próprias características da composição paratática, conforme La Fauci (2007). Defendo, de maneira a ser esclarecida, que a produtividade da parataxe nos enunciados escritos reflete a produtividade da parataxe nos enunciados falados, e que esse reflexo, longe de ser uma questão de interferência, é marca da constituição mista entre as duas modalidades de enunciação. $\mathrm{Na}$ outra via, na seção 7.3, exploro a representação cognitiva de relações de sentido, visando avaliar o grau de complexidade. Para tanto, opto particularmente pelo exame da representação da condicionalidade.

\subsection{A composição paratática}

Nesta seção, discuto as construções paratáticas mais recorrentes no corpus, com o propósito de explicitar alguns dos traços linguísticos desse tipo de composição nos textos infantis. Os fragmentos de textos de (1) a (3) 7 exemplificam um pouco da

${ }^{7}$ Para apresentação dos exemplos, sigo a seguinte convenção: indico primeiramente o escrevente (E1 e E2), depois o número da proposta (P1 a P55), e então o ano de realização (A1 a A4).

${ }^{8}$ Outros trabalhos já evidenciaram a natureza multifacetada de "e", como é o caso de Schneuwly (1988, apud Rojo, 2007), que investigou textos explicativo-argumentativos e constatou que: "Uma unidade, dentre os organizadores textuais, apresenta dificuldades particulares quanto a sua categorização: o E. (...) O E se encontra tanto em contextos lógico-semânticos, quanto temporo-causais. Do ponto de vista ontogenético, o E parece desempenhar um papel muito particular. Todos os autores o consideram o primeiro conectivo, como o "paradigma dos relatores", como o "arquiconectivo": ele propõe um modelo de conexão e parece ser uma unidade a partir da qual se diferenciam numerosas outras." polissemia ${ }^{8}$ do juntor " $e$ ", para o qual estabeleci uma tipologia de valores baseada em traços da construção que ele ajuda a formar. Em (1), " $\mathrm{e}$ " organiza as orações numa sequência temporal que reflete a ordem dos eventos no mundo. Em (2), a sucessão temporal veiculada pelas orações implica uma leitura de causa e efeito. Em (3), o que vem antes e o que vem depois no tempo se traduzem, respectivamente, em causa e efeito que, por sua vez, implicam condição. Em todo corpus, as polissemias são frequentes, principalmente as de trânsito entre Tempo e Causa, revelando relações de parentesco semântico e recapitulando assim tendências em gramaticalização de juntores (KORTMANN, 1997). O critério para classificação dos casos ambíguos foi sempre o nível mais alto, conforme Esquema 2, elaborado para o Texto 3.

Texto (1): [E1/P11:A1]

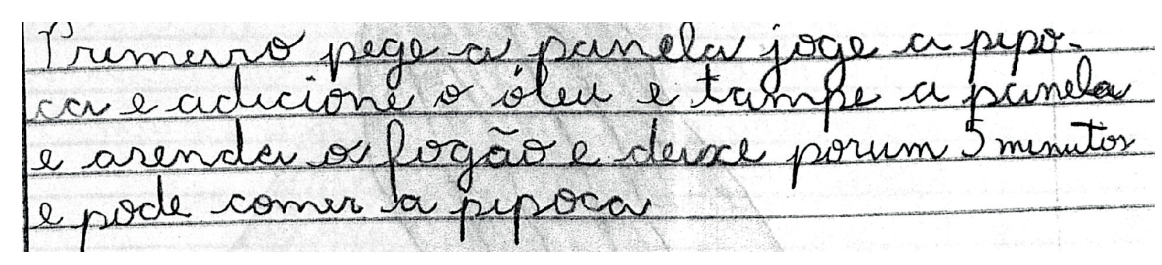


Texto (2): [E1/P24:A2]

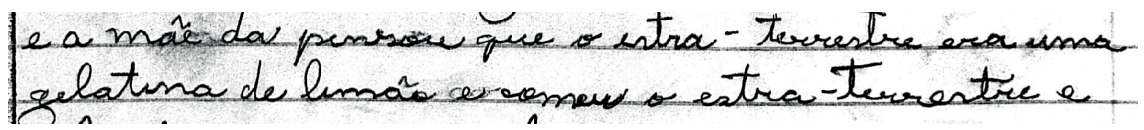

Texto (3):[E1/P8:A1]

\begin{tabular}{|c|c|}
\hline \multicolumn{2}{|l|}{ Oenge } \\
\hline 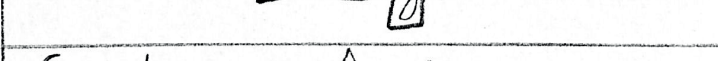 & \\
\hline \multirow{2}{*}{\multicolumn{2}{|c|}{ 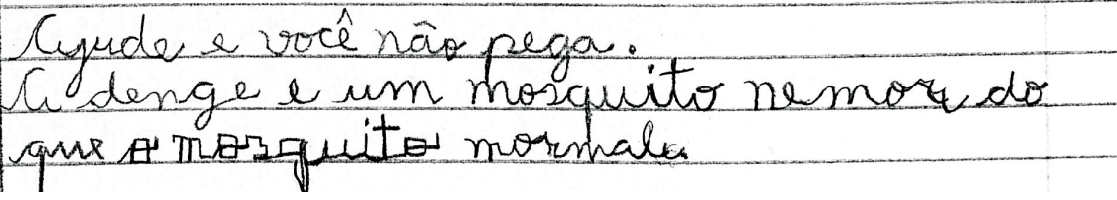 }} \\
\hline & \\
\hline 3. Se você ajuda, não pega (condição) & Aumento \\
\hline 2. Porque você ajuda, não pega (causa/efeito) & \\
\hline 1. Quando você ajuda, não pega ( tempo) & \\
\hline
\end{tabular}

Esquema 02: Parentesco entre as relações semânticas (KORTMANN, 1997)

A opção pela parataxe com $e$, e o uso desse juntor repetidamente em várias fronteiras oracionais são traços muito recorrentes nos textos infantis, e as amostras em (4) e (5), a seguir, são outros bons exemplares. A recorrência de $e$ pode ser interpretada como indício dos rituais das tradições da oralidade, sobretudo de uma oralidade informal, que recupera gêneros primários, como o diálogo cotidiano familiar. Nesses termos, a morfossintaxe dos textos infantis traz marcas da encenação dos diálogos pelos quais se conta uma história, se passa uma receita, se explica as etapas de um jogo, se argumenta em favor de um ponto de vista. São rituais que visam, entre outras coisas, entendimento e memorização.

Texto 4: [E1/P5:A01]

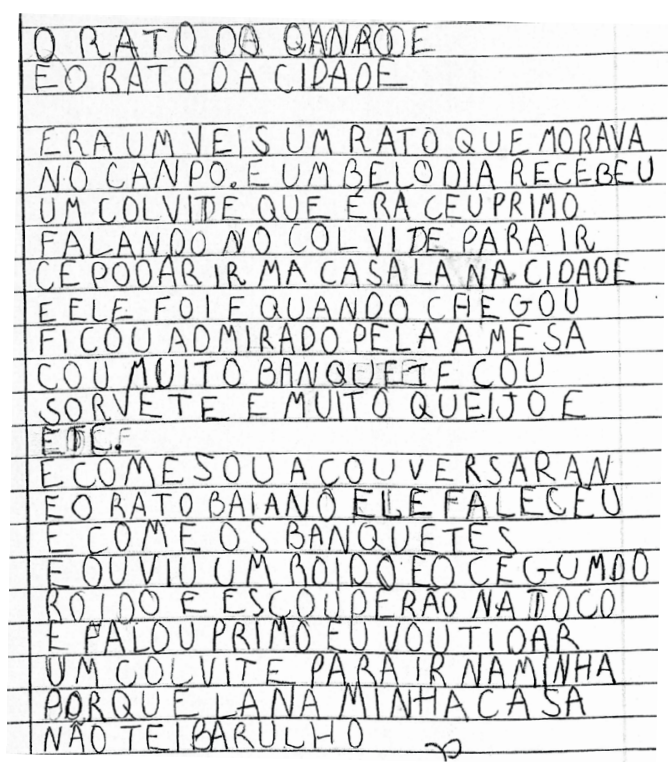

O rato do campo e

E o rato da cidade

Era uma vez um rato que morava no campo. E um belo dia recebeu um convite que era de seu primo falando no convite para ir, se puder, na casa lá na cidade. E ele foi e quando chegou ficou admirado pela mesa com muito banquete, com sorvete e muito queijo e etc.

\section{E começou a conversar} $\mathrm{E}$ o rato baiano ele faleceu E comem os banquetes E ouviram um ruído e o segundo ruído e esconderam na toca E falou primo eu vou te dar um convite para ir na minha [casa] porque lá na minha casa não tem barulho. 
Texto 5: [E2:P27:A2]

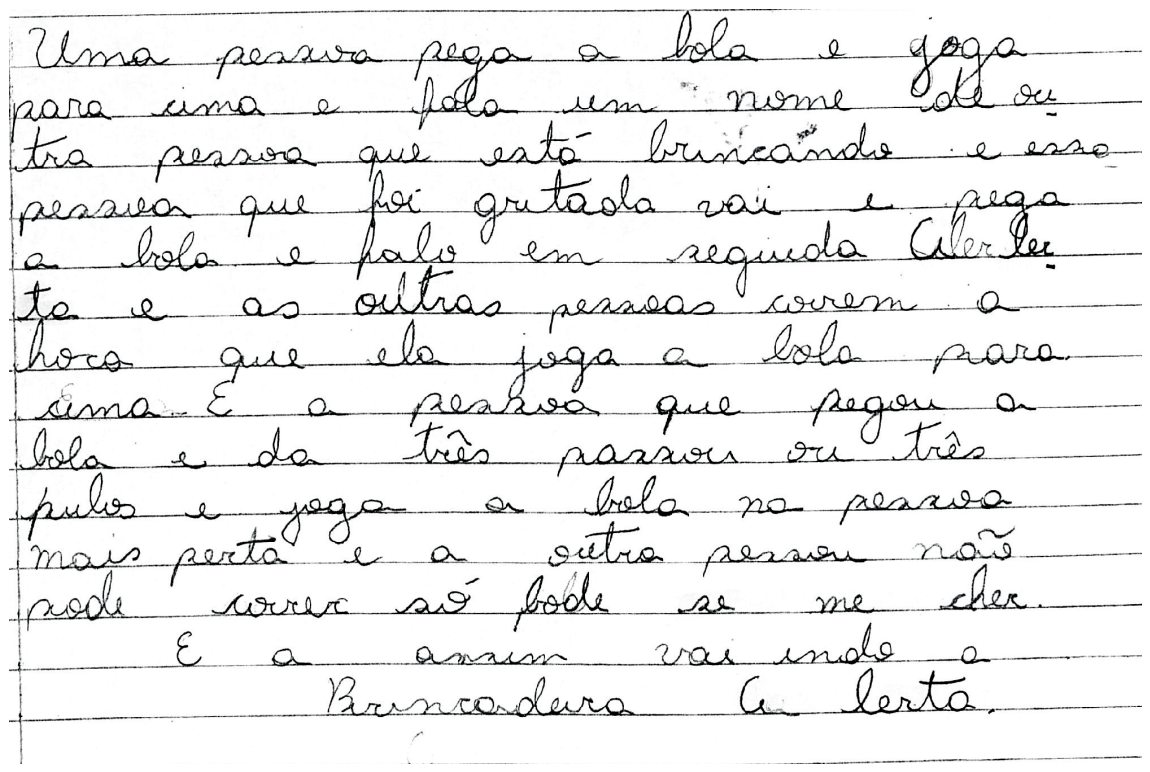

Nos casos de parataxe por justaposição, seguindo Taboada (2009), priorizei o reconhecimento das pistas de natureza morfológica, sintática e semântica que indiciam o sentido, na ausência de juntores. Nos dados investigados, as pistas mais comuns se referem: à negativa explícita aliada ao paralelismo sintático para marcação de contraste, como em (6), cuja leitura é: não deixe a garrafa com a boca para cima $\varnothing$ o certo é para baixo; à ordem das orações para marcação de sequência temporal, como em (7), à ordem das orações aliada ao conhecimento de mundo (de que pessoas desempregadas não têm dinheiro), como em (9), para indicação de causa e efeito; à semântica dos verbos (passa, atravessa, vai, entra) para o sequenciamento no tempo, como em (7); e ao contexto prévio com juntor explícito, como em (8), cuja leitura é se eu falo abacaxi, eu vou.

Texto (6): [E2/P8:A1]

NAO DEICHA A GARAEA COM A BOCA PARA GIMA
O CÉTO É PARALBAICHO.

Texto (7): [E2/P46:A4] 


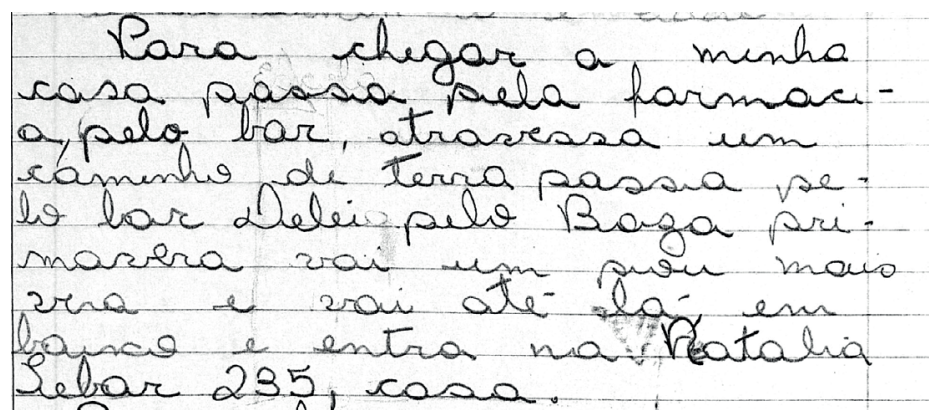

Texto (8): [E2/P26:A2]

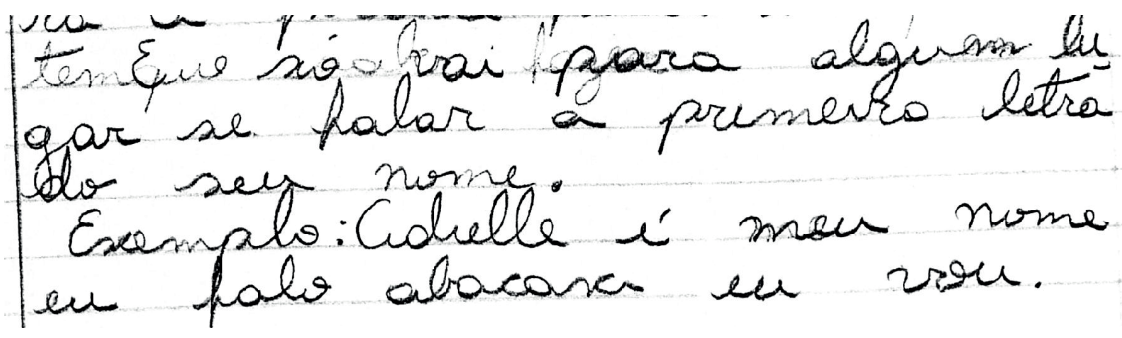

Texto (9): [E1/P31:A3]

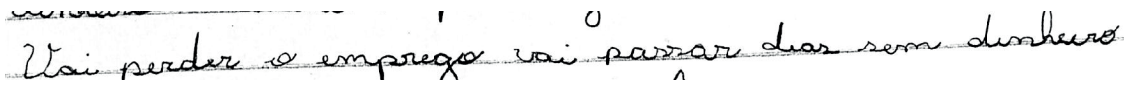

A análise das construções paratáticas sugere complexidade, pois:

(i) a parataxe consiste fundamentalmente em uma composição binária em que a ordem icônica das orações, fundada em restrições tempo-causais, é invariável, o que não se aplica à hipotaxe, cuja liberdade relativa pode gerar diferentes efeitos de sentido;

(ii) a parataxe comporta implícitos: como se realiza mais frequentemente por meio do polissêmio $e$ e da justaposição, ou seja, com o mínimo de material morfológico, a parataxe exige mais cálculo de sentido. Seguindo La Fauci (2007), quanto menos uma construção é evidente formal e/ou semanticamente, mais sua determinação é difícil. Na oralidade, essa sintaxe menos explícita é compensada pela entoação e gestos;

(iii) a parataxe consiste em uma estratégia de diálogo, uma vez que, sendo necessária a mobilização de inferências, exige uma colaboração mais ativa do interlocutor, propriedade que ajuda a explicar sua recorrência em tradições da oralidade;

(iv) a parataxe consiste em uma estratégia de memorização: o trabalho de elaboração mental, exigido por uma sintaxe menos explícita, tende a resultar em uma maior fixação dos 
fatos na memória, propriedade que também ajuda a explicar a recorrência na oralidade.

\subsection{Correlação Junção e TD}

Para explicitar a correlação entre junção e TD nos textos infantis, selecionei três textos representativos das tradições narrativa, relato de palestra e relato de procedimento e, a partir deles, elaborei Juntogramas, gráficos bidimensionais que trazem, no eixo superior, as opções de articulação paratática e hipotática, que são cruzadas, no eixo inferior, com as relações semânticas. Os juntogramas apresentam um mapeamento detalhado dos esquemas de junção de um texto, sendo possível recuperar frequência, tipos e distribuição dos juntores empregados.

O confronto entre os gráficos sinaliza, de modo geral, que na narrativa e no relato de procedimento predominam os esquemas paratáticos de temporalidade, enquanto, no relato de palestra, há maior diversidade de relações semânticas, com frequências mais significativas, inclusive para a hipotaxe.

Juntograma 1: [E1/P06:A1]

Juntograma 2: [E1/P:01A1]

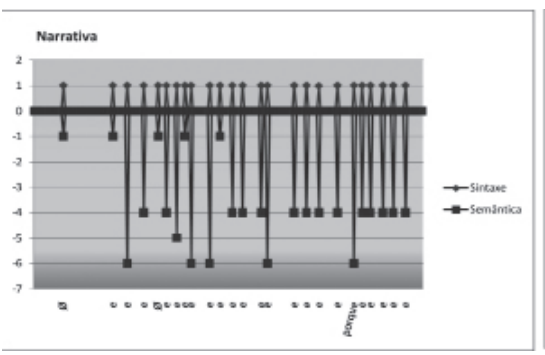

Juntograma 3: [E1/P11:A1]

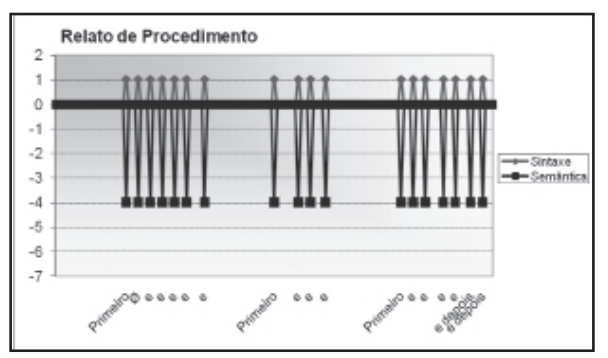

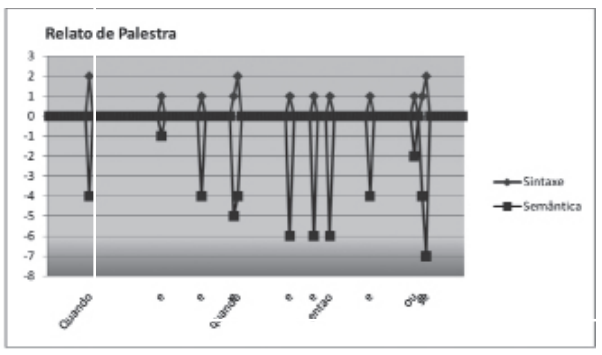

Legenda

Eixo superior:

$1=$ parataxe; 2 = hipotaxe

Eixo inferior:

-1 = adição; -2 = alternância;

$-3=$ modo; -4 tempo;

$-5=$ contraste; -6 = causa;

$-7=$ condição

O juntograma 1 resulta de um texto cuja proposta de produção consistiu na leitura da história dos três porquinhos e na posterior elaboração de outra versão, com novas complicações e novo desfecho. No juntograma prevalecem relações temporais, o que sugere que a criança se insere na escrita, circulando pelo fixo da tradição de contar, ao mostrar que sabe ordenar os eventos no tempo, e circulando também pelo lacunar, ao eleger preferencialmente a parataxe, baseando-se assim em regras de tradições da oralidade as quais domina. 
Explicação similar vale para o relato de procedimento. $\mathrm{O}$ juntograma 3 mapeia um texto que apresenta três receitas culinárias. Os três "blocos" de juntores refletem uma das partes características da TD receita, que é o "modo do preparo", enquanto os espaços vazios se referem à "lista de ingredientes", porção sem juntores. Novamente, são as relações de tempo que estruturam o texto e a criança vai optar por parataxe temporal. Já o texto 2 tem um propósito diferente, nele a criança deve reproduzir seu entendimento a respeito de uma palestra. Ojuntograma 2 mostra uma diversidade de junção bem maior, com construções paratáticas e hipotáticas que dão conta da codificação de várias relações semânticas: alternância, modo, tempo, contraste, causa e condição.

A análise permite afirmar que, na produção dos primeiros textos escritos, a criança vai lidar de modo singular com o fixo e com o lacunar das tradições, fazendo transparecer o caráter processual da aquisição, que se revela (i) tanto na transposição que é feita da modalidade de enunciação (falada), que ela domina, para a modalidade em aquisição (escrita), o que corrobora a asserção de Street (2006) de que a escrita se desenvolve no interior de um sistema oral de pensamento que permanece dominando os usos do letramento; (ii) quanto nas decisões pelos mecanismos de junção, em que a criança faz uma diferenciação semântica considerável por meio de recursos morfossintáticos mínimos.

\subsection{Representação cognitiva da condicionalidade}

A expressão da condicionalidade em português conta com um repertório extenso de juntores, dentre os quais, se, caso, contanto que, desde que, uma vez que, sem que, dado que, a não ser que, a menos que, exceto se. São na grande maioria juntores condicionais complexos, que podem mobilizar arquiteturas sintáticas diferenciadas, com nuanças semântico-pragmáticas particulares.

O quadro 2, apresentado anteriormente, mostra que as condicionais têm uso reduzido no corpus e que a escolha no conjunto dos juntores é bastante restrita, sendo a hipotaxe com se - juntor prototípico - o recurso mais empregado. Montolio (2000) reconhece que os conectivos condicionais complexos são menos frequentes em registros orais e espontâneos e, retomando Wing e Kofsky (1981), argumenta que, dada a complexidade formal e a especificidade da relação condicional que esses conectivos introduzem, estão entre as construções adquiridas pelas crianças em estágios mais avançados, posteriormente às estruturas equivalentes a se e às estruturas paratáticas.

As construções com se, tal como mostradas nos textos, podem ser tomadas como índices de como as crianças flutuam pelas regras idiomáticas, sobretudo nas correlações envolvendo a morfologia verbal, necessárias para indicação dos diferentes 
graus de hipótese. A esse respeito (01) e (02) são ilustrativos, já que o futuro do subjuntivo da primeira oração não encontra correspondência, segundo as regras da língua, no futuro do presente perifrástico, empregado pela criança. Além disso, em casos como (03), é a variação linguística que está em jogo: a conjugação do verbo é representativa de variedades não-padrão.

(01) [E1/P25:A2] se o lula fosse presidente o Brasil vai ficar mais com segurança.

(02) [E1/P35:A3] se eles tivessem um filho vai sair um mini microfone.

(03) [E2/P28:A2] se você vim você será bem vinda na nossa classe

Na articulação paratática, conforme as ocorrências (04) e (05) já discutidas em seção prévia, a leitura condicional se deve ao vínculo semântico de causa e efeito, que resulta da ordem icônica das orações e dos pressupostos envolvidos.

(04) [E1/P8:A1] Dengue. Ajude e você não pega.

(05) [E2/P26:A2] Exemplo: Adielle é meu nome Ø eu falo abacaxi eu vou.

Há também leituras condicionais que derivam de construções hipotáticas temporais com quando em que, construídas preferencialmente com verbos no presente, deixam de implicar factualidade e codificam eventualidade. São condicionais que expressam habitualidade, parafraseáveis por sempre que, como em (06) a (08).

(06) [E1:P2/A1] Quando tem dor de ouvido, tem água suja

(07) [E1:P7/A1] Quando as antas vão caçar, elas trombam em tudo

(08) [E1:P7/A1] Quando chove, o sal espalha

Para os propósitos do presente trabalho, interessa verificar a representação cognitiva da condicionalidade, ou seja, se as relações de condição são estabelecidas entre os conteúdos semanticamente relacionados das orações, em que o conteúdo da segunda oração é efeito ou consequência do conteúdo da primeira, ou se as condicionais são estabelecidas entre etapas do processo de raciocínio do escrevente, em que um conhecimento ou suposição é condição para o julgamento ou conclusão. A expectativa, vale reforçar, é a de que os processos de raciocínio subjacentes às condicionais epistêmicas envolvam maior complexidade cognitiva e por isso sejam codificados mais tardiamente.

$\mathrm{Na}$ análise das ocorrências, o resultado é categórico: os textos infantis apresentam somente condicionais de conteúdo, estabelecidas no domínio sociofísico, a partir de uma relação de 
causa > efeito entre eventos do mundo, como exemplificam as ocorrências de (09) a (12). A menor complexidade morfossintática das construções condicionais e a menor complexidade cognitiva da condicionalidade, observadas nos primeiros anos de letramento formal, são aspectos que direcionam para a confirmação da correlação entre tendências filogenéticas e ontogenéticas. A aquisição das relações epistêmicas é mais tardia e provavelmente depende da aquisição de outras TDs.

(09) [E1/P26:A2] a pessoa fala cão e se a primeira letra do nome for "c" você fala: "você vai a lua".

(10) [E2/P22:A2] se você não parar de falar isso eu vou te dar um tiro.

(11) [E2/P44:A4] se você não me beijar eu te mato

(12) [E1/P45:A4] se você comprar à vista você recebe um desconto

\section{Considerações finais}

Neste trabalho, investiguei aspectos do processo de aquisição da modalidade de enunciação escrita, em perspectiva longitudinal, com atenção aos mecanismos de junção. A opção pela junção não foi gratuita, uma vez que: (i) os juntores são itens funcionais (significação interna), da gramática da língua, que supostamente impõem maiores dificuldades de aquisição do que os itens lexicais (significação externa); (ii) a junção é um fenômeno que permite explorar as faces morfossintática e semântico-cognitiva; (iii) a junção é de importância singular para a apreensão das TDs.

As formas de junção empregadas nos textos de escrita inicial infantil trazem marcas da experiência que as crianças tiveram até então com tradições da oralidade. $\mathrm{O}$ mecanismo por excelência é a parataxe, bastante característico de enunciações faladas, não por se tratar de uma sintaxe simples ou menos rica, mas por ser uma composição fundada numa forma de diálogo, com encadeamentos que favorecem a memorização. Portanto, a prevalência da parataxe no computo geral dos dados não causa surpresa, já que era esperado encontrar textos híbridos, com traços de uma oralidade informal e também de uma oralidade formal, como, por exemplo, a oralidade letrada da professora.

Também não é surpresa a codificação das relações semânticas em nível menos abstrato, em que as condicionais epistêmicas, no âmbito do raciocínio lógico, não foram mostradas. Contudo, quebrou expectativas o fato de que o tempo de letramento formal pouco ou nada contribuiu, no caso das crianças investigadas, para a ampliação no quadro da junção, para a aquisição de novas construções morfossintáticas com nuanças semânticas várias. Isso realmente põe em questão o papel da escola. 
Tendências ontogenéticas puderam ser vislumbradas, já que na escrita inicial predominaram juntores de menor complexidade morfológica e de relativa complexidade cognitiva. Mas o trabalho contribuiu, sobretudo, para mostrar a necessidade de considerar, nesse tipo de investigação, o peso das TDs, a relação fala/escrita e a importância de uma compreensão mais circunstanciada das construções de junção. A decisão por um esquema de junção, em dado estágio de aquisição, pode decorrer da complexidade da construção em jogo, mas também de características funcionais do próprio esquema de junção, que é mais ou é menos adequado a um "modo de dizer".

\begin{abstract}
In this work, I start out from a junction to investigate possible correlations between the underlying trends in the use of the junction mechanisms in subject texts during the writing acquisition stage, as well as trends in the development of junctures in language history. In a certain way, the purpose is to bring new light to the parallel between ontogeny and phylogeny, as proposed by Kortmann (1997), who supports, for the acquisition of junction schemes and for the change of junctures over time, directions which signal a growing complexity, verifiable both through a morphosyntactic and cognitive-semantic point of view.
\end{abstract}

Keywords: acquisition; junction; cognition; history

\title{
REFERÊNCIAS
}

ABAURRE, M. B. M. Língua oral, língua escrita: interessam, à linguística, os dados da aquisição da representação escrita da linguagem? Em: Anais do IX Congresso Internacional da Alfal. Campinas: IEL/Unicamp, 1990.

BIBER, D. Variation across speech and writing. Cambridge: Cambridge University Press, 1988.

CORRÊA, M. L. O modo heterogêneo de constituição da escrita. São Paulo: Martins Fontes, 2004.

HALLIDAY, M.A.K. An introduction to functional Grammar, London: Edward Arnold, 1985. 
KABATEK, J. Tradições discursivas e mudança linguística. In: Lobo, T; Ribeiro, I.; Carneiro, Z.; Almeida, N. (Orgs.) Para a história do português brasileiro. Salvador, EDUFBA, tomo II, 2006.

$\mathrm{KOCH}, \mathrm{P}$. Diskurstraditionen: zu ihrem sprachtheoretischen Status und ihrer Dynamik. In: Frank et al. (Orgs.) p. 43-79, 1997.

$\mathrm{KOCH}, \mathrm{P} ; \mathrm{OESTERREICHER,} \mathrm{W.} \mathrm{Schriftlichkeit} \mathrm{und} \mathrm{Sprache.} \mathrm{In:}$ Günther; Ludwig (Eds.), Vol. I:587-604, 1994.

KOCH, P; OESTERREICHER, W. Lingua hablada en la Romania: Espanol, Francés, Italiano. Madrid: Editorial Gredos, 2007.

KORTMANN, B. Adverbial subordination: a typology and history of adverbial subordinators based on European languages. Berlin, NY: Mounton de Gruyter, 1997.

LA FAUCI, N. Paradoxes de la parataxe. In: Béguelin, M.; Avanzi, M; Corminboeuf, G. (Eds.) Actes du colloque international "la parataxe", Université de Neuchâtel, 2007.

MARCUSCHI, L. A. Oralidade e escrita. Natal: UFRN. (Conferência pronunciada no I Colóquio Franco-Brasileiro sobre linguagem e Educação, em Natal, 23-26 de junho de 1995), mimeo, 17 p;

MARTIN, J. R. et. al. Working with functional grammar. London/NY: Auckland Arnold, 1997.

MONTOLIO, E. On affirmative and negative complex conditional connectives. In: Couper-Kuhlen, E.; Kortmann, B. (eds). Cause, condition, concession, contrast: cognitive and discourse perspectives. Berlin, New York: Mouton de Gruyter, 2000.

OESTERREICHER, W. Zur Fundierung von Diskurstraditionen. In: HAYE, T.; TOPHINKE, D. (eds) Gattungen mittelalterlicher Schriftlichkeit, p. 19-41, 1997.

ROJO, R. R. A emergência da "coesão" narrativa: "e daí" em narrativas infantis. In: CASTILHO, A.; MORAIS, M.A.; LOPES, R.E.; CYRINO, S. (ogs) Descrição, história e aquisição do português do brasileiro. Campinas/SP: Pontes, 617-632, 2007.

STREET, B. Perspectivas interculturais sobre o letramento. Filologia e Linguística Portuguesa, vol. 8, São Paulo: Humanitas/FFLCH/USP, p. 465-488, 2006.

SWEETSER, E. From etymology to pragmatics. Cambridge: Cambridge University Press, 1991.

TABOADA, M. Implicit and explicit coherence relations. In: Renkema, J. (ed.) Discourse, of course: an overview of research in discourse studies. Amsterdam/Philadelphia: John Benjamins Publishing Company, 2009. 